\title{
Pseudoexfoliation and Blood Flow Abnormalities
}

\section{Rita Ehrlich, Alon Harris, Carlos Rospigliosi López, Nisha S Kheradiya}

Department of Ophthalmology, Indiana University School of Medicine, Indianapolis, IN, USA

\section{INTRODUCTION}

Pseudoexfoliation syndrome is the most common clinical precursor to secondary open-angle glaucoma worldwide. ${ }^{1}$ It is a systemic disease that is characterized by the progressive accumulation of whitish-grey fibrillar proteins in various organs, especially ocular tissues, such as the lens, pupil border, zonules, orbital tissues, and trabecular meshwork. It is a major risk factor for glaucoma development; therefore, early detection is important in order to monitor signs of disease progression and to initiate aggressive medical and/or surgical therapies.

Pseudoexfoliation syndrome prevalence increases with age and is associated with elevated intraocular pressures. Many studies, such as the Thessaloniki Eye Study ${ }^{2}$ and Blue Mountain Eye Study, ${ }^{3}$ have found that pseudoexfoliation syndrome prevalence varies from 2.3 to $11.9 \%$ amongst different populations. ${ }^{4-13}$ Furthermore, 14.2 to $55.1 \%$ of patients with pseudoexfoliation syndrome are likely to progress into openangle glaucoma. ${ }^{2,14}$ The Early Manifest Glaucoma found that pseudoexfoliation is a strong predictor of glaucoma progression independent of elevated intraocular pressures and other risk factors. ${ }^{15}$ Additionally, pseudoexfoliation has also been shown to be an important independent risk factor for glaucoma development in patients with ocular hypertension. ${ }^{14}$ In 14 to $29 \%$ of cases, pseudoexfoliation syndrome progresses from a unilateral disease to bilateral disease. ${ }^{16,17}$

The pseudoexfoliative deposits are composed of complex glycoprotein/proteoglycan molecules, bearing similarities to epitopes within the basement membrane and the elastic fiber system. ${ }^{18}$ These microfibrillar subunits are surrounded by an amorphous matrix of elastic fibers (such as elastin, tropoelastin, amyloid $\mathrm{P}$, and vitronectin) and elastic microfibrils (such as fibrillin-1, microfibril-associated glycoprotein-1, and latent tumor growth factor-binding proteins). ${ }^{18}$ The nature of pseudoexfoliative material and the stimulus for its production are unknown. ${ }^{19}$ Imbalances between matrix metalloproteinases and tissue inhibitors of matrix metalloproteinases and extensive cross-linking processes are involved in pseudoexfoliative fiber formation, whereby the pathologic material is not properly degraded but instead progressively accumulates within the tissues over time. ${ }^{20}$ Furthermore, the accumulation of these pseudoexfoliation deposits within the pericellular region can disrupt the underlying basement membrane and lead to a degenerative fibrillopathy ${ }^{21-23}$ and dysfunction of the vasculature. Over time, the blood vessels experience reduced contractility and elasticity, which can eventually lead to alterations in blood flow velocity (Fig. 1).

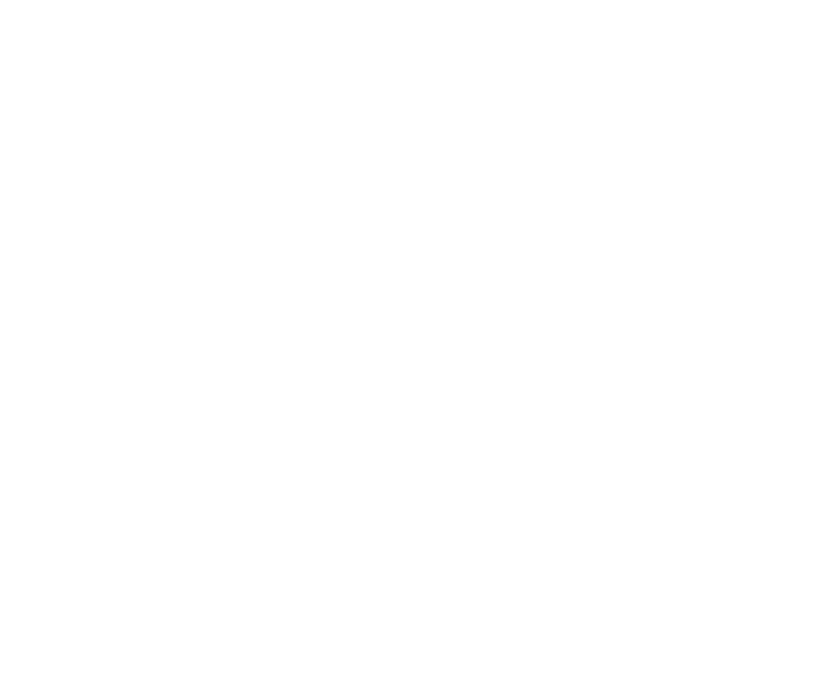

Proposed role of decreased blood flow in the development of pseudoexfoliation glaucoma

Fig. 1: In pseudoexfoliation syndrome, pseudoexfoliation material deposits in various ocular tissues. As pseudoexfoliation material accumulates in the trabecular meshwork, it increases resistance to aqueous fluid outflow, which leads to an increase in intraocular pressure. Accumulation of the same material in blood vessels leads to a decrease in vessel contractility and loss of elasticity. This can lead to an increase in vascular resistance and decrease in the ocular blood flow. Both the increase in intraocular pressure and decrease in ocular blood flow have been linked to retinal and optic nerve head ischemia and apoptosis of the retinal ganglion cells through glutamate release and NMDA receptor activation. This can account for the conversion of pseudoexfoliation syndrome to pseudoexfoliation glaucoma 
The hallmark of pseudoexfoliation disease is the pathologic production and accumulation of abnormal fibrillar extracellular material in the anterior segment tissues. ${ }^{24}$ Pseudoexfoliation material deposits throughout the trabecular meshwork can result in blockage of the outflow channels of aqueous fluid. More specifically, abnormal accumulation of pseudoexfoliation matter in the juxtacanalicular tissue beneath the inner wall of Schlemm canal has been shown to lead to the greatest resistance to the aqueous fluid outflow. ${ }^{25}$ Increased outflow resistance and decreased aqueous fluid drainage results in the chronic intraocular pressure elevations. The progressive buildup of pseudoexfoliation material in the juxtacanalicular tissue has been shown to correlate with elevated intraocular pressures and the presence and increased severity of glaucomatous optic nerve changes. $^{25,26}$ Pseudoexfoliation glaucoma is characterized by the presence of pseudoexfoliative debris on the lens and/or pupillary border, increased pigmentation at the angle, glaucomatous optic disk changes, and glaucomatous visual field defects. ${ }^{27}$ It is associated with higher mean intraocular pressures, greater diurnal fluctuations in intraocular pressure, marked pressure spikes, and poorer responses to medical intraocular pressure-reducing therapies, all of which can account for its worse prognosis than primary open-angle glaucoma. ${ }^{28,29}$ Although psuedoexfoliation syndrome significantly predisposes patients to pseudoexfoliation glaucoma, not all patients with pseudoexfoliation syndrome will develop glaucomatous signs/symptoms. Active involvement of the trabecular meshwork may lead to glaucoma development in 40 to $60 \%$ of the patients. ${ }^{30}$

Pseudoexfoliation syndrome is the ocular manifestation of a systemic disease; therefore, pseudoexfoliative material deposits are not only found within orbital tissue, but can also accumulate in skin, lung, heart, liver, gallbladder, kidney, ear, optic nerve, blood vessels, and cerebral meninges. ${ }^{24,31-34}$ Although pseudoexfoliation syndrome is diagnosed through ocular signs/ symptoms, correlations have been made between the ocular changes and systemic diseases. In this review, we will focus on the less discussed vascular and blood flow changes associated with pseudoexfoliation syndrome and its correlation with pseudoexfoliation glaucoma and other systemic vascular-related abnormalities.

\section{THE OCULAR VASCULATURE}

Pseudoexfoliation syndrome represents a disease continuum that progresses as extracellular material accumulates in the vasculature. Although pseudoexfoliation syndrome is often unilateral when first detected, ${ }^{35,36}$ recent studies illustrate the subclinical involvement within the unaffected eyes. ${ }^{37}$ Kivela et al found the abnormalities within the ocular vasculature are detected earlier than frank pseudoexfoliation deposits on the ciliary epithelium and lens capsule. ${ }^{37}$ Furthermore, the severity of pseudoexfoliation glaucoma was found to be related to the amount of pseudoexfoliation material present in the cribriform region. ${ }^{19}$ Nevertheless, since it is not currently possible to determine the length of time a patient has been exposed to pseudoexfoliation syndrome, varying degrees of pseudoexfoliative material accumulation may explain the differing results produced while investigating pseudoexfoliation syndrome.

With advanced glaucomatous damage, there is reduced blood flow in the lamina cribrosa and the rim area but not in the peripapillary retina. ${ }^{38}$ Pseudoexfoliation syndrome is also associated with a thinner retinal nerve fiber layer compared to controls. ${ }^{39}$ Puska et al demonstrated that patients with pseudoexfoliation syndrome may experience structural optic disc changes that were unrelated to increased intraocular pressure. $^{40}$

Accumulation of pseudoexfoliation material has been associated with narrowing and hypoperfusion of the iris vessels, loss of normal radial iris vessels, and neovascularization. ${ }^{41-44}$ In pseudoexfoliation syndrome, affected iris vessels show prominent pseudoexfoliation material accumulations in the adventitia, gradual degeneration of smooth muscle cells, pericytes, and endothelial cells up to complete destruction of the iris vessel wall or complete obliteration of the vessel lumen. ${ }^{24}$

Dayanir et al studied the ocular blood flow changes in patients with unilateral pseudoexfoliation syndrome between eyes clinically affected by pseudoexfoliation syndrome versus clinically unaffected eyes and controls. ${ }^{46}$ In eyes affected by pseudoexfoliation material, the ophthalmic artery experienced decreases in the peak systolic and end diastolic velocities and increases in the resistive index compared to the control group. Moreover, comparison of the clinically unaffected eyes with the control group showed significant decreases in mean peak systolic velocity by $23 \%$ and in end diastolic velocity by $40 \%$ of the ophthalmic artery. Thus, even unilateral pseudoexfoliation disease seems to affect the ocular tissue and vasculature in both eyes, even if not yet clinically detectable. Unilateral pseudoexfoliation syndrome converts to pseudoexfoliation glaucoma in the contralateral eye in up to third of cases ${ }^{47}$ and understanding pathologic alterations in the clinically unaffected eye at the initial presentation can provide further insights into the possible pathogenesis of disease progression.

Pseudoexfoliation deposits have been reported within the central retinal artery, short posterior ciliary arteries and vortex veins. ${ }^{48}$ Saatci et al pointed out that pseudoexfoliation syndrome is a risk factor for central retinal vein occlusion. ${ }^{45}$

Altered ocular blood flow has been widely reported in glaucoma patients and with glaucoma progression. ${ }^{49-51}$ Patients with pseudoexfoliation syndrome and iris transillumination have a significantly higher resistive index of the ophthalmic artery than controls. ${ }^{52}$ Pulsatile ocular blood flow, a representation of choroidal blood flow, was found to be decreased in pseudoexfoliation glaucoma compared to controls. ${ }^{53}$ No 
differences in pulsatile ocular blood flow were found between pseudoexfoliation syndrome patients when compared to pseudoexfoliation glaucoma patients. ${ }^{53}$ Yüksel et al used color Doppler imaging to demonstrate that pseudoexfoliation syndrome patients had decreased peak systolic velocity in the central retinal artery, decreased end diastolic blood flow velocities in the central retinal and short posterior ciliary arteries and high resistive indices in the ophthalmic and central retinal arteries. ${ }^{48}$ Pseudoexfoliation glaucoma patients also showed decreased blood flow velocities and increased resistive indices in the ophthalmic, central retinal and short posterior ciliary arteries when compared to controls. ${ }^{48,54}$ Moreover, patients with pseudoexfoliation glaucoma had lower blood flow velocities in the ophthalmic and short nasal posterior ciliary arteries than patients with pseudoexfoliation syndrome. ${ }^{54}$ Since the blood flow velocity changes are less severe in pseudoexfoliation syndrome, it may be considered a precursor to pseudoexfoliation glaucoma (Table 1). Nevertheless, it cannot be determined if these alterations in blood flow velocities contribute to the pathogenesis of pseudoexfoliation glaucoma or if they are a consequence of the disease.

A controversy remains over the differences in blood flow velocity between pseudoexfoliation and primary open-angle glaucoma. Yuksel et al found that blood flow velocities decreased to the same degree in patients of both groups. ${ }^{54}$ On the other hand, Martinez et al reported that blood flow abnormalities are more pronounced in primary open-angle glaucoma compared to pseudoexfoliation glaucoma ${ }^{55}$ (Table 1). These findings suggest that although the well-recognized parameter in the pathogenesis of pseudoexfoliation glaucoma

Table 1: Summary of ocular and cerebral blood flow changes in patients with pseudoexfoliation

\begin{tabular}{|c|c|c|c|}
\hline Study & Subjects & Technology & Blood flow changes and area/vessels involved \\
\hline \multicolumn{4}{|c|}{ Ocular Blood Flow Changes } \\
\hline Mistlberger et $\mathrm{al}^{53} 2001$ & $\begin{array}{l}17 \text { PXG vs } \\
17 \text { PXS vs } \\
11 \text { controls }\end{array}$ & POBF & $\begin{array}{ll}\text { - } & \downarrow \mathrm{PV} \text { and POBF in PXG than in controls } \\
\text { - } & \text { No difference in PA, PV, and POBF between PXG and PXS }\end{array}$ \\
\hline Yüksel et $\mathrm{al}^{48} 2001$ & $\begin{array}{l}14 \text { PXG vs } \\
14 \text { PXS vs } \\
14 \text { controls }\end{array}$ & - CDI & $\begin{array}{ll}\text { - } & \downarrow \text { PSV of CRA, } \downarrow \text { EDV of CRA and TPCA, } \uparrow \text { RI of OA and CRA in } \\
& \text { PXS than controls } \\
\text { - } & \downarrow \text { PSV, } \downarrow \text { EDV, } \uparrow \text { RI of OA, CRA, PCA in PXG than controls } \\
\text { - } & \downarrow \text { PSV and } \downarrow \text { EDV of OA and NPCA in PXG compared to PXS patients }\end{array}$ \\
\hline Yüksel et $\mathrm{al}^{54} 2001$ & $\begin{array}{l}26 \text { PXG vs } \\
28 \text { POAG vs } \\
30 \text { controls }\end{array}$ & $-\quad$ CDI & $\begin{array}{ll}\text { - } & \downarrow \text { PSV of CRA and PCA in PXG than in controls } \\
\text { - } & \downarrow \text { EDV and } \uparrow \text { RI of OA, CRA and PCA in PXG compared to controls } \\
& \text { No difference in blood flow velocities between PXG and POAG } \\
\text { patients }\end{array}$ \\
\hline Martinez et al $^{55} 2006$ & $\begin{array}{l}43 \text { PXG vs } \\
31 \text { POAG }\end{array}$ & $-\quad$ CDI & - $\uparrow \mathrm{PSV}, \uparrow \mathrm{EDV}$ and $\downarrow$ RI of OA and PCA in PXG compared to POAG \\
\hline Galassi et al $^{56} 2007$ & $\begin{array}{l}47 \text { PXG vs } \\
41 \text { POAG vs } \\
38 \text { controls }\end{array}$ & $\begin{array}{l}- \\
\text { - } \\
\text { ODI } \\
\text { from systemic } \\
\text { blood pressure and } \\
\text { IOP }\end{array}$ & $\begin{array}{ll}\text { - } & \downarrow \text { EDV and } \uparrow \text { RI of CRA and PCA in PXG compared to POAG and } \\
& \text { controls } \\
\text { - } & \downarrow \text { EDV of OA in PXG compared to controls } \\
\text { - } & \uparrow P S V \text { and } \uparrow \text { RI of OA in PXG than POAG or controls } \\
\text { - } & \text { Lower OPP and DPP in PXG than POAG and controls }\end{array}$ \\
\hline \multicolumn{4}{|c|}{ Cerebral Blood Flow Velocity Changes } \\
\hline Akarsu et $\mathrm{al}^{27} 2005$ & $\begin{array}{l}19 \text { PXG vs } \\
19 \text { controls }\end{array}$ & $-\mathrm{TCD}$ & $\begin{array}{l}\text { - } \downarrow \text { PSV, } \downarrow \text { EDV }, \downarrow \text { TAMAX, } \uparrow \text { RI, and } \uparrow \text { PI of MCA in PXG compared to } \\
\text { controls }\end{array}$ \\
\hline Yüksel et $\mathrm{al}^{65} 2006$ & $\begin{array}{l}24 \text { PXG vs } \\
25 \text { PXS vs } \\
25 \text { controls }\end{array}$ & - TCD & $\begin{array}{l}\text { - } \quad \downarrow_{\mathrm{MSV}} \text { and } \downarrow \text { MDV of MCA in PXG and PXS eyes compared to } \\
\text { controls } \\
\text { - } \quad \text { No difference in blood flow velocities between PXG and PXS patients }\end{array}$ \\
\hline
\end{tabular}

PXG - pseudoexfoliation glaucoma; PXS - pseudoexfoliation syndrome; POAG - primary open-angle glaucoma; POBF - pulsatile ocular blood flowmetry/flow; PV - pulse volume; PA - pulse amplitude; CDI - color Doppler imaging; PSV - peak systolic velocity; EDV - end diastolic velocity; RI - resistive index; OA - ophthalmic artery; CRA - central retinal artery; PCA - posterior ciliary arteries; TPCA - temporal posterior ciliary arteries; NPCA - nasal posterior ciliary arteries; OPP - ocular perfusion pressure; BP - blood pressure; DPP - diastolic perfusion pressure; TCD transcranial Doppler; TAMAX - time-averaged maximum velocity; PI - pulsatility index; MCA - middle cerebral artery; MSV - mean systolic velocity; MDV - mean diastolic velocity. 
is elevated intraocular pressure and resulting glaucomatous damage, microcirculatory dysfunction and reduced blood flow velocities in the retrobulbar vessels may contribute to glaucomatous optic nerve damage in patients with pseudoexfoliation glaucoma. ${ }^{54}$

Although color Doppler indices are direct measurements of blood flow velocities, these can only be used as estimations for actual blood flow. Since direct visualization of ocular blood flow is not currently available, clinical practitioners can use blood pressure and intraocular pressure measurements to calculate ocular perfusion pressure to quantify vascular changes in glaucomatous patients. Ocular perfusion pressure is defined as $2 / 3$ of the mean arterial blood pressure minus intraocular pressure. This can be further broken down into the systolic and diastolic components by taking the systolic or diastolic blood pressure minus the intraocular pressure, respectively. Hence, ocular perfusion pressure can be decreased by raising the intraocular pressure or reducing the blood pressure. Recently, Galassi et al reported that both the ocular perfusion pressure and diastolic perfusion pressures were lower in the pseudoexfoliation glaucoma group than in primary openangle glaucoma patients or controls. ${ }^{56}$ In the same study, decreased end diastolic velocities and increased resistive indices were found in the ophthalmic, central retinal, and short posterior ciliary arteries in patients with pseudoexfoliation glaucoma. ${ }^{56}$ The perfusion pressure was further negatively related to the resistive index of the ophthalmic artery in patients with pseudoexfoliation glaucoma, with no similar relationships in patients with primary open-angle glaucoma or controls. ${ }^{56}$ (Table 1) Therefore, alterations in optic nerve head blood supply or ocular blood flow dysfunctional autoregulation seem to play a role in pseudoexfoliation glaucoma.

Many factors can affect ocular vasculature and various studies have shown that ocular blood vessel autoregulation may be disturbed in glaucoma patients. For example, aqueous humor analysis of patients with normotensive pseudoexfoliation demonstrated increased levels of endothelin-1, a potent vasoconstrictor, ${ }^{57}$ and decreased levels of nitric oxide, a potent physiologic vasodilator. ${ }^{58}$ This imbalance can disrupt vascular autoregulation and play a role in causing local ischemia early in the disease process. ${ }^{18}$ This further suggests that vascular dysregulation, impaired parasympathetic drive, or deposition of pseudoexfoliation material within the vasculature can reduce blood flow to the optic nerve head and may be implicated in the pathogenesis of pseudoexfoliation glaucoma. . $4,59-64$

\section{THE CEREBRAL VASCULATURE}

Since both the brain and the retina have the same embryologic development, there are close similarities between their vasculatures. Often, the middle cerebral artery blood flow is used as a representation of overall cerebral blood flow. In patients with pseudoexfoliation glaucoma, middle cerebral artery blood flow velocities were decreased and the resistive and pulsatility indicies were increased when compared to controls. ${ }^{27}$ Yüksel et al compared middle cerebral artery blood flow amongst patients with pseudoexfoliation syndrome, pseudoexfoliation glaucoma and control subjects. ${ }^{65}$ In the pseudoexfoliation glaucoma group, the mean systolic and diastolic velocities in the middle cerebral artery were found lower than the control group. ${ }^{65}$ No difference was found between the group of subjects with pseudoexfoliation glaucoma or syndrome ${ }^{65}$ (Table 1). Decreases in cerebral blood flow have been reported in various types of glaucoma, such as normal-tension, low-tension and primary open-angle glaucoma, and not just in pseudoexfoliation glaucoma. ${ }^{66-68}$ Studying the effect of intraocular pressure on cerebral blood flow found that patients with ocular hypertension did not have similar changes in cerebral blood flow as patients with glaucoma. ${ }^{69}$ This implies that increases in intraocular pressure is not the only factor connected to the decrease in cerebral blood flow, and that disease itself is related to the decrease in blood flow. In addition, magnetic resonance imaging of normal-tension glaucoma patients demonstrates diffuse cerebral small vessel ischemic change, cerebral infarcts, or corpus callosum atrophy. ${ }^{69,70}$ Therefore, altered cerebral blood flow velocities are not only associated with pseudoexfoliation disease, but also with various forms of glaucoma.

Repo et al evaluated the effect of pseudoexfoliation syndrome on the vascular tissue in patients who had at least one transient ischemic attack. ${ }^{52}$ Iris transillumination and pseudoexfoliation syndrome were significantly higher in these patients with transient ischemic attacks compared to healthy subjects. ${ }^{52}$ This may suggest pathologic changes in the blood supply of pseudoexfoliation syndrome eyes. Ritland et al investigated the survival and cause of death of 1147 patients with pseudoexfoliation glaucoma or primary open-angle glaucoma. ${ }^{61}$ There was increased comorbidity but not mortality in patients with pseudoexfoliation glaucoma and acute cerebrovascular disease, as well as with chronic cerebral diseases such as senile dementia, cerebral atrophy and chronic cerebral ischemia. ${ }^{61}$

Recently, it has been reported that pseudoexfoliation syndrome was associated with Alzheimer's disease. Stroman et $\mathrm{al}^{71}$ suggests pseudoexfoliation-associated lesions are also located in the brain of patients suffering from dementia. The Alzheimer's peptide $(A \beta)$ has been detected in the aqueous humor of pseudoexfoliation patients. ${ }^{71}$ In Alzheimer's disease, $\mathrm{A} \beta$ peptides are deposited in the neuritic plaques and cerebral vessel walls and are associated with a reduction of cerebrovascular blood flow. ${ }^{72,73}$ Although age, gender, systemic blood pressure, carotid artery stenosis, diabetes mellitus, blood viscosity, increased intracranial pressure, and systemic 
medications can affect blood flow velocities, most studies attempt to eliminate these differences in their patient populations in order to determine statistically significant variations. Therefore, it is possible that these two diseases share some common pathophysiology and similar biochemical and etiological features. ${ }^{70,74}$

\section{OTHER VASCULAR SYSTEMS}

Many studies have demonstrated a correlation between pseudoexfoliation syndrome and cardiovascular disease. Mild to moderate hyperhomocysteinemia has been suggested as one possible cause for an increased vascular risk in pseudoexfoliation patients. ${ }^{18}$ Pathologic elevation of plasma homocysteine concentrations in patients with pseudoexfoliation syndrome independent of glaucomatous change has been demonstrated in different studies. ${ }^{75-79}$ Homocysteine can play a role in altering extracellular matrix metabolism through the dysregulation of matrix metalloproteinases, their inhibitors, and in vascular endothelial dysfunction. ${ }^{18}$ Vitamins $\mathrm{B}_{6}, \mathrm{~B}_{12}$, and folate are involved in homocysteine metabolism and they have been reported to be markedly decreased in patients with pseudoexfoliation glaucoma. ${ }^{18}$ Since they are also negatively correlated with total plasma homocysteine levels, deficiencies of these vitamins may explain hyperhomocysteinemia in these patients. ${ }^{18}$ In a different report folate and serum vitamin $\mathrm{B}_{6}$ and $\mathrm{B}_{12}$ levels did not differ statistically between the pseudoexfoliation group and the control group. ${ }^{78}$ But further research will be necessary to confirm this association, since another study did not find a statistically significant correlation between homocysteine and vitamins $\mathrm{B}_{6}, \mathrm{~B}_{12}$, and folate levels in pseudoexfoliation patients.

Furthermore, cutaneous microcirculation of patients with pseudoexfoliation shows altered response to cold and warm conditions compared to patients with primary open-angle glaucoma and controls. The altered response may suggest damage to the vascular autonomic innervation and/or damage to the microcirculatory effector system. ${ }^{80}$ Visontai et al recently reported that increased carotid artery stiffness and reduced baroreflex sensitivity in patients with pseudoexfoliation syndrome and glaucoma. ${ }^{64}$ These findings can suggest altered parasympathetic vascular control in pseudoexfoliation disease which increases with age.

These findings suggest that ocular pseudoexfoliation is a part of a general disorder of the extracellular matrix and that these patients may suffer from increased comorbidity ${ }^{18}$ In the Blue Mountain Eye Study, pseudoexfoliation syndrome was associated with a history of angina or hypertension or a combined history of angina, acute myocardial infarction, or stroke, which further emphasizes the systemic and potentially vascular nature of pseudoexfoliation syndrome. ${ }^{60}$ Citirik et al ${ }^{81}$ reported higher presence of pseudoexfoliation syndrome in patients with coronary artery disease and a higher occurrence of coronary artery disease in patients with pseudoexfoliation syndrome. They suggest that all patients with pseudoexfoliation syndrome be screened for coronary artery disease and patients with coronary artery disease be screened for pseudoexfoliation syndrome. $^{81}$

\section{CONCLUSION}

In the past few years, it becomes clear that glaucoma in a multifactorial disease and lowering intraocular pressure is not always sufficient. ${ }^{82,83}$ Growing evidence supports the role of vascular abnormalities in glaucoma disease and progression. ${ }^{49,84}$ It seems that pseudoexfoliation syndrome and glaucoma have a vascular component to disease development and progression. Although pseudoexfoliation glaucoma is differentiated from primary openangle glaucoma both clinically and histopathologically, both have similar blood flow abnormalities and elevated intraocular pressure. It is possible that the ocular blood flow is influenced by the elevated intraocular pressure, but pseudoexfoliation material found in the vascular walls may also lead to impaired blood flow both systemically and locally in the eye (see Fig. 1). It is unknown whether the vascular changes seen in pseudoexfoliation are adherent abnormalities or perhaps secondary to altered dysregulation due to endothelial dysfunction. Ocular blood flow reduction can be seen in the pseudoexfoliation syndrome and glaucoma. Perhaps both the vascular and intraocular pressure components have to occur mutually as the pseudoexfoliation material accumulates during development of glaucoma disease and progression. It seems that variations in optic nerve head blood supply and in ocular blood flow regulation play also a role in pseudoexfoliation glaucoma. ${ }^{56}$ With further research, future clinical practices may include routine ophthalmologic examinations to identify this important marker for patients at risk for cerebrovascular and cardiovascular disease.

\section{REFERENCES}

1. Ritch R. The most common identifiable cause of open angle glaucoma. J Glaucoma 1994;3:176-8.

2. Topouzis F, Wilson MR, Harris A, et al. Prevalence of openangle glaucoma in Greece: the Thessaloniki Eye Study. American Journal of Ophthalmology 2007;144(4):511-9.

3. Mitchell P, Wang JJ, Hourihan F. The relationship between glaucoma and pseudoexfoliation: the Blue Mountain Eye Study. Archives of Ophthalmology 1999;117(10):1319-24.

4. Arnarsson A, Damji KF, Sverrisson T, et al. Pseudoexfoliation in the Reykjavik Eye Study: prevalence and related ophthalmological variables. Acta Ophthalmologica Scandinavica 2007;85(8):822-7.

5. Rao RQ, Arain TM, Ahad MA. The prevalence of pseudoexfoliation syndrome in Pakistan. Hospital based study. BMC Ophthalmology 2006;6:27. 
6. Miyazaki M, Kubota T, Kubo M, et al. The prevalence of pseudoexfoliation syndrome in a Japanese population: the Hisayama study. Journal of Glaucoma 2005;14(6):482-4.

7. Thomas R, Nirmalan PK, Krishnaiah S. Pseudoexfoliation in southern India: the Andhra Pradesh Eye Disease Study. Investigative Ophthalmology and Visual Science 2005;46(4):1170-6.

8. Young AL, Tang WW, Lam DS. The prevalence of pseudoexfoliation syndrome in Chinese people. British Journal of Ophthalmology 2004;88(2):193-5.

9. Arvind H, Raju P, Paul PG, et al. Pseudoexfoliation in South India. British Journal of Ophthalmology 2003;87(11):1321-3.

10. Ramakrishna R, Nirmalan PK, Krishnadas R, et al. Glaucoma in a rural population of southern India: the Aravind comprehensive Eye Survey. Ophthalmology 2003;110(8):1484-90.

11. Sainz Gomez C, Moreno-Montanes J, Escudero Berasategui $\mathrm{JM}$, et al. Prevalence and risk factors of pseudoexfoliation syndrome in institutionalized geriatric patients in Navarra. Archivos de la Sociedad Espanola de Oftalmologia 2003;78(7):383-8.

12. Krishnadas R, Nirmalan PK, Ramakrishnan R, et al. Pseudoexfoliation in a rural population of southern India: the Aravind Comprehensive Eye Survey. American Journal of Ophthalmology. 2003;135(6):830-7.

13. Mccarty CA, Taylor HR. Pseudoexfoliation syndrome in Australian adults. American Journal of Ophthalmology 2000;129(5):629-33.

14. Grodum K, Heijl A, Bengtsson B. Risk of glaucoma in ocular hypertension with and without pseudoexfoliation. Ophthalmology 2005;112(3):386-90.

15. Leske MC, Heijl A, Hussein M, et al. Factors for glaucoma progression and the effect of treatment: The Early Manifest Glaucoma Trial. Am J Ophthalmol 2003;121:48-56.

16. Henry JC, Krupin T, Schmitt M, et al. Long-term follow-up of pseudoexfoliation and the development of elevated intraocular pressure. Ophthalmology 1987;94(5):545-52.

17. Jeng SM, Karger RA, Hodge DO, et al. The risk of glaucoma in pseudoexfoliation syndrome. Journal of Glaucoma 2007;16(1):117-21.

18. Schlötzer-Schrehardt U, Naumann GO. Ocular and systemic pseudoexfoliation syndrome. Am J Ophthalmol 2006; 141(5):921-37.

19. Gottanka J, Flügel-Koch C, Martus P, et al. Correlation of pseudoexfoliative material and optic nerve damage in pseudoexfoliation syndrome. Invest Ophthalmol Vis Sci 1997;38(12):2435-46.

20. Zenkel M, Poschl E, von der Mark K, et al. Differential gene expression in pseudoexfoliation syndrome. Invest Ophthalmol Vis Sci 2005;46:3742-52.

21. Eagle RC, Font RL, Fine BS. The basement membrane exfoliation syndrome. Arch Ophthalmol 1979;97:510-15.

22. Khalil AK, Kuboto T, Tawara A, et al. Early changes in iris blood vessels in exfoliation syndrome. Curr Eye Res 1998;17:1124-34.
23. Li ZY, Streeten BW, Wallace RN. Association of elastin with pseudoexfoliative material: an immunoelectron microscopic study. Curr Eye Res 1998;7:1163-72.

24. Naumann GOH, Schotzer-Schrehardt U, Kuchle M. Pseudoexfoliation syndrome for comprehensive ophthalmologist. Intraocular and systemic manifestations. Ophthalmology 1998;105:951-68.

25. Schlotzer-Schrehardt U, Naumann GOH. Trabecular meshwork in pseudoexfoliation syndrome with and without open-angle glaucoma: a morphometric, ultrastructural study. Invest Ophthalmol Vis Sci 1995;36:1750-64.

26. Gottanka J, Flugel-Koch C, Martus P. Correlation of pseudoexfoliative material and optic nerve damage in pseudoexfoliation syndrome. Invest Ophthalmol Vis Sci 1997;38:2435-46.

27. Akarsu C, Unal B. Cerebral haemodynamics in patients with pseudoexfoliation glaucoma. Eye 2005;19(12):1297-300.

28. Konstas AGP, Stewart WC, Stromann GA. Clinical presentation and initial treatment patterns in patients with exfoliation glaucoma versus primary open-angle glaucoma. Ophthalmol Surg Lasers 1997;28:111-7.

29. Konstas AGP, Mantziris DA, Stewart WC. Diurnal intraocular pressure in untreated exfoliation and primary open-angle glaucoma. Arch Ophthalmol 1997;115:182-5.

30. Schlotzer-Schrehardt U, Kuchle M, Junemann A, et al. Relevance of the pseudoexfoliation syndrome for the glaucomas. Ophthalmologe 2002;99(9):683-90.

31. Streeten BW, Dark AJ, Wallace RN, et al. Pseudoexfoliative fibrillopathy in the skin of patients with ocular pseudoexfoliation. Am J Ophthalmol 1990;110:490-99.

32. Cahill M, Early A, Stack S, et al. Pseudoexfoliation and sensorineural hearing loss. Eye 2002;16:261-6.

33. Streeten BW, Li ZY, Wallace RN, et al. Pseudoexfoliative fibrillopathy in visceral organs of a patient with pseudoexfoliation syndrome. Arch Ophthalmol 1992;110:1757-62.

34. Schlotzer-Schrehardt U, Koca MR, Naumann GOH, et al. Pseudoexfoliation syndrome. Ocular manifestation of a systemic disorder? Arch Ophthalmol 1992;110:1752-56.

35. Mitchell P, Wang JJ, Hourihan F. The relationship between glaucoma and pseudoexfoliation syndrome: the Blue Mountain Eye Study. Arch Ophthalmol 1999;117:1319-24.

36. Shimizu K, Kimura Y, Aoki K. Prevalence of exfoliation syndrome in the Japanese. Acta Ophthalmol 1988;184:112-5.

37. Kivela T, Hietanen J, Uusitalo M. Autopsy analysis of clinically unilateral exfoliation syndrome. Invest Ophthalmol Vis Sci 1997;38:2008-15.

38. Harju M, Vesti E. Blood flow of the optic nerve head and peripapillary retina in exfoliation syndrome with unilateral glaucoma or ocular hypertension. Graefes Arch Clin Exp Ophthalmol 2001;239(4):271-7.

39. Yuksel N, Altintas O, Celik M, et al. Analysis of retinal nerve fiber layer thickness in patients with pseudoexfoliation syndrome using optical coherence tomography. Ophthalmologica 2007;221(5):299-304. 
40. Puska P, Vesti E, Tomita G, et al. Optic disc changes in normotensive persons with unilateral exfoliation syndrome: a 3year follow-up study. Graefes Arch Clin Exp Ophthalmol 1999;237(6):457-62.

41. Konstas AGP, Marshall GE, Cameron SA, et al. Morphology of iris vasculopathy in exfoliation glaucoma. Acta Ophthalmol 1993;71:751-9.

42. Asano N, Schlotzer-Schrehardt U, Naumann GOH. A histopathologic study of iris changes in pseudoexfoliation syndrome. Ophthalmology 1995;102:1279-90.

43. Helbig H, Schlotzer-Schrehardt U, Noske W, et al. Anteriorchamber hypoxia and iris vasculopathy in pseudoexfoliation syndrome. Ger J Ophthalmol 1994;3:148-53.

44. Repo LP, Terasvirta ME, Kivisto KJ. Generalized transluminance of iris and frequency of the pseudoexfoliation syndrome in the eyes of transient ischemic attack patients. Ophthalmology 1993;100:352-5.

45. Saatçi OA, Ferliel ST, Ferliel M, et al. Pseudoexfoliation and glaucoma in eyes with retinal vein occlusion. International Ophthalmolgy 1999;23:75-78.

46. Dayanir V, Topaloglu A, Ozsunar Y, et al. Orbital blood flow parameters in unilateral pseudoexfolation syndrome. Int Ophthalmol 2008; Epub ahead of print.

47. Puska PM. Unilateral exfoliation syndrome: conversion to bilateral exfoliation and to glaucoma-a prospective 10-year follow-up study. J Glaucoma 2002;11:517-24.

48. Yüksel N, Karaba L, Arslan A, et al. Ocular hemodynamic in pseudoexfoliation syndrome and pseudoexfoliation glaucoma. Ophthalmology 2001;108:1043-9.

49. Galassi F, Sodi A, Ucci F, Renieri G, Pieri B, Baccini M. Ocular hemodynamic and glaucoma prognosis. A color Doppler imaging study. Arch Ophthalmol 2003;121:1711-5.

50. Zeitz O, Galambos P, Wagenfeld L, Wiermann A, Wlodarsch P, Praga , Matthiessen ET, Richards G, Klemm M. Glaucoma progression is associated with decreased blood flow velocities in the short posterior ciliary artery. Br J Ophthalmol 2006;90:12458.

51. Plange N, Kaup M, Arend O, Remky A. Asymmetric visual field loss and retrobulbar haemodynamics in primary open angle glaucoma. Graefes Arch Clin Exp Ophthalmol 2006;244:97883.

52. Repo LP, Suhonen MT, Terasvirta ME, et al. Color Doppler imaging of the ophthalmic artery blood flow spectra of patients who have had a transient ischemic attack. Opthalmology 1995;102:1199-1205.

53. Mistlberger A, Grunchmann M, Hitzl W, Grabner G. Pulsatile ocular blood flow in patients with pseudoexfoliation. Int Ophthalmol 2001;23:337-42.

54. Yüksel N, Karaba VL, Demirci A, et al. Comparison of blood flow velocities of the extraocular vessels in patients with pseudoexfoliation or primary open angle glaucoma. Ophthalmologica 2001;215:424-9.

55. Martinez A, Sanchez M. Ocular haemodynamics in pseudoexfoliative and primary open-angle glaucoma. Eye 2006 Dec 15: doi:10.1038/sj.eye.6702676.
56. Galassi F, Giambene B, Menchini U. Ocular perfusion pressure and retrobulbar haemodynamics in pseudoexfoliative glaucoma. Graefes Arch Clin Exp Ophthalmol 2007;246(3):411-6.

57. Koliakos GG, Konstas AGP, Schlötzer-Schrehardt U, et al. 8-Isoprostaglandin F2A and ascorbic acid concentration in the aqueous humor of patients with exfoliation syndrome. $\mathrm{Br} \mathrm{J}$ Ophthalmol 2003;87:353-6.

58. Kotikoski H, Moilanen E, Vapaatalo H, et al. Biochemical markers of the L-arginine-nitric oxide pathway in the aqueous humour in glaucoma patients. Acta Ophthalmol Scand 2002;80:191-5.

59. Irkec M. Exfoliation and carotid stiffness. Br J Ophthalmol 2006;90:529-30.

60. Mitchell P, Wang JJ, Smith W. Association of exfoliation syndrome with increased vascular risk. Am J Ophthalmol 1997;124:685-7.

61. Ritland JS, Egge K, Lydersen S, et al. Exfoliative glaucoma and primary open-angle glaucoma: associations with death cause and comorbidity. Acta Ophthalmol Scand 2004;82:401-4.

62. Shrum KR, Hattenhauer MG, Hodge D. Cardiovascular and cerebrovascular mortality associated with ocular pseudoexfoliation. Am J Ophthalmol 2000;129:83-6.

63. Streeten BW, Gibson SA, Dark AJ. Pseudoexfoliative material contains an elastic microfibrillar-associated glycoprotein. Trans Am Ophthalmol 1986;84:304-20.

64. Visontai Z, Merisch B, Kollai M, et al. Increase of carotid artery stiffness and decrease in baroreflex sensitivity in exfoliation syndrome and glaucoma. Br J Ophthalmol 2006;90:563-7.

65. Yüksel N, Anik Y, Kiliç A, et al. Cerebrovascular blood flow velocities in pseudoexfoliation. Graefe's Arch Clin Exp Ophthalmol 2006;244:316-21.

66. Linner E, Popovic V, Gottffries CG, et al. The exfoliation syndrome in cognitive impairment of cerebrovascular or Alzheimer's type. Acta Ophthalmol Scand 2001;79:283-5.

67. Jellinger KA. The pathology of ischemic-vascular dementia: an update. J Neurol Sci 2002; 203-204:153-7.

68. Kudo T, Imaizumi K, Tanimukai H, et al. Are cerebrovascular factors involved in Alzheimer's disease? Neurobiol Aging 2000;21:215-24.

69. Harris A, Zarfati D, Zalish M, et al. Reduced cerebrovascular blood flow velocities and vasoreactivity in open angle glaucoma. Am J Ophthalmol 2003;135:144-7.

70. Onk K, Farinelli A, Billson F, et al. Comparative study of brain magnetic resonance imaging findings in patients with low-tension glaucoma and control subjects. Ophthalmology 1995;102:16328.

71. Stroman GA, Stewart WC, Golnic KC, et al. Magnetic resonance imaging in patients with low tension glaucoma. Arch Ophthalmol 1995;113: 168-72.

72. Akarsu C, Bilgili YK, Unal B, et al. Cerebral hemodynamics in ocular hypertension. Graefes Arch Clin Exp Ophthalmol 2005;243(4):317-20.

73. Janciauskiene S, Krakau T. Alzheimer's peptide: a possible link between glaucoma, exfoliation syndrome and Alzheimer's disease. Acta Ophthalmol Scand 2001;79:328-9. 
74. Janciauskiene S, Krakau T. Alzheimer's peptide and serine proteinase inhibitors in glaucoma and exfoliation syndrome. Doc Ophthalmol 2003;106:215-23.

75. Bleich S, Junemann A, von Ahsen N, et al. Homocysteine and risk of open-angle glaucoma. J Neural Transm 2002;109:499504.

76. Leibovirch I, Kurtz S, Shemesh G, et al. Hyperhomocysteine is elevated in patients with exfoliation syndrome. Am J Ophthalmol 2003;12:36-9.

77. Vessani RM, Ritch R, Liebmann J, et al. Plasma homocysteine is elevated in patients with exfoliation syndrome. Am J Ophthalmol 2003;136:41-6.

78. Puustjarvi T, Blomster H, Kontkanen M, et al. Plasma and aqueous humour levels of homocysteine in exfoliation syndrome. Graefes Arch Clin Exp Ophthalmol 2004;242:749-54.

79. Altintas O, Maral H, Yuksel N, et al. Homocysteine and nitric oxide levels in plasma of patients with pseudoexfoliation syndrome, pseudoexfoliation glaucoma, and primary open-angle glaucoma. Graefes Arch Clin Exp Ophthalmol 2005;243:67783.

80. Holló G, Lakatos P, Farkas K. Cold pressor test and plasma endothelin-1 concentration in primary open-angle and capsular glaucoma. J Glaucoma 1998;7(2):105-10.

81. Citirik M, Acaroglu G, Batman C et al. A possible link between the pseudoexfoliation syndrome and coronary artery disease. Eye 2007;21:11-15.
82. Leske MC, Heijl A, Hyman L, Bengtsson B, Dong L, Yang Z. EMGT Group. Predictors of long-term progression in the early manifest glaucoma trial. Ophthalmology 2007;114:1965-72.

83. Collaborative Normal Tension Glaucoma Study Group. The effectiveness of intraocular pressure reduction in the treatment of normal tension glaucoma. Am J Ophthalmol 1998;126:498505.

84. Martínez A, Sánchez M. Predictive value of colour Doppler imaging in a prospective study of visual field progression in primary open-angle glaucoma. Acta Ophthalmol Scand 2005;83:716-22.

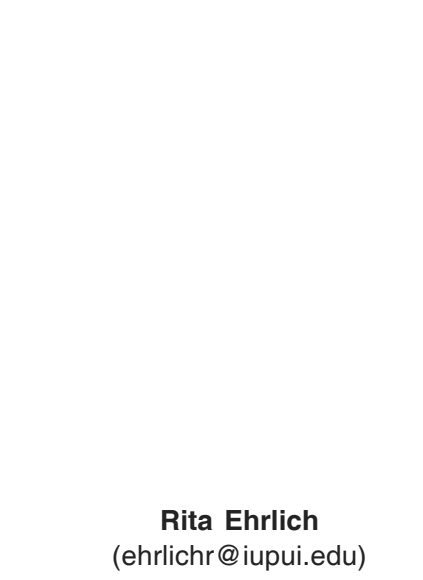

I want it said of me by those who knew me best, that I always plucked a thistle and planted a flower, where I thought a flower would grow. 